\section{Commentary: Don't fear the nonsteroidal anti-inflammatory drugs}

\author{
Jennie H. Kwon, MD, and Chadrick E. Denlinger, MD
}

The opioid epidemic has devastated communities across our nation during the past 2 decades, and surgeons have been called on to prescribe opioids more responsibly. The Enhanced Recovery After Surgery (ERAS) Society has responded to this call to action with publication of perioperative protocols that encourage multimodal analgesia to minimize opiate consumption. For example, a recently published ERAS protocol for esophagectomy recommends several analgesic agents, including thoracic epidural anesthesia, paravertebral blocks, acetaminophen, and nonsteroidal anti-inflammatory drugs (NSAIDs), among others, in addition to opioids reserved only for breakthrough pain. ${ }^{1}$ Obviously, shifts in practice patterns must be evaluated for unknown hazards, and perioperative NSAID use has been associated with increased rates of anastomotic leak in colorectal and bariatric surgeries. ${ }^{2}$ Most recently, a retrospective study from the Danish National Patient Registry found that ketorolac and other NSAIDs dramatically increased the rate of anastomotic leak following an esophagectomy. ${ }^{3}$

Given these concerning findings, Corsini and colleagues ${ }^{4}$ retrospectively evaluated the influence of ketorolac use following esophagectomy, reviewing the rate of anastomotic leak in a cohort of 1019 patients over a 13-year period at the MD Anderson Cancer Center. They found that despite a near-doubling in the rate of ketorolac use in patients after esophagectomy, rates of anastomotic leak decreased over the study period from $15 \%$ in 2006 to $2 \%$ in 2018 . On multivariate analysis, ketorolac use was not associated with anastomotic leak nor was there a dose-dependent association.

\footnotetext{
From the Division of Cardiothoracic Surgery, Medical University of South Carolina, Charleston, SC.

Disclosure: Authors have nothing to disclose with regard to commercial support

Received for publication Feb 26, 2020; revisions received Feb 26, 2020; accepted for publication Feb 26, 2020; available ahead of print March 19, 2020.

Address for reprints: Chadrick E. Denlinger, MD, Division of Cardiothoracic Surgery, Department of Surgery, Medical University of South Carolina, 114 Doughty St, Charleston, SC 29425 (E-mail: denlinge@musc.edu).

J Thorac Cardiovasc Surg 2021;161:455-6

$0022-5223 / \$ 36.00$

Copyright (c) 2020 by The American Association for Thoracic Surgery

https://doi.org/10.1016/j.jtcvs.2020.02.125
}

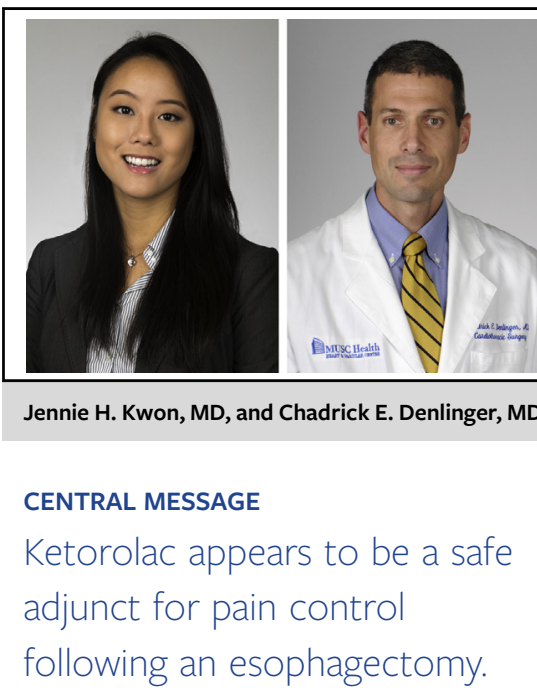

This study addresses the important issue of postoperative pain management in an era where we have recognized the risks of opiates. However, it is likely inadequately powered to detect any difference in rates of anastomotic leak between patients who did or did not receive ketorolac. Though the cohort includes more than 1000 patients, the study population varies widely. Patients varied in treatment paradigm (upfront surgery vs neoadjuvant chemoradiation followed by surgery) and surgical approach (minimally invasive vs open, Ivor Lewis vs transhiatal and 3-field). During the study period, the practices of detecting anastomotic leak shifted from routine screening in all patients to selective evaluation of only suspected leaks. Further, it is uncertain whether their adoption of ERAS practices during the study period not only led to more frequent use of ketorolac but also encouraged other significant modifications in postoperative management such as timing of oral intake or length of postoperative nasogastric tube decompression.

The ERAS paradigm attempts to standardize perioperative care for patients and is certainly positioned to address the national opioid crisis with recommendations for postoperative analgesia. Developed by a working group of thoracic and upper gastrointestinal surgeons, anesthesiologists, and nurses, the ERAS guidelines for perioperative esophagectomy care are formulated from available literature. However, we must remain vigilant for unforeseen consequences while applying these protocols, which are only just that. As practice patterns shift to multimodal analgesia and increased use of NSAIDs, we should be cautious to assess individual patient risk for gastric irritation, platelet dysfunction and postoperative bleeding, or renal dysfunction, and perhaps now also for anastomotic leak. 


\section{References}

1. Low DE, Allum W, Manzoni GD, Ferri L, Immanuel A, Kuppusamy M, et al. Guidelines for perioperative care in esophagectomy: Enhanced Recovery After Surgery (ERAS $($ ) Society recommendations. World J Surg. 2018;43:299-330.

2. Klein M, Gogenur I, Rosenberg J. Postoperative use of nonsteroidal antiinflammatory drugs in patients with anastomotic leakage requiring reoperation after colorectal resection: cohort study based on prospective data. BMJ. 2012;345:e6166.
3. Fjederholt KT, Okholm C, Svendsen LB, Achiam M, Kirkegård J, Mortensen FV, et al. Ketorolac and other NSAIDs increase the risk of anastomotic leakage after surgery for GEJ cancers: a cohort study of 557 patients. J Gastrointest Surg. 2017;22: 587-94.

4. Corsini EM, Hofstetter WL. The MD Anderson Esophageal Cancer Working Group; Ketorolac use and anastomotic leak in patients with esophageal cancer. J Thorac Cardiovasc Surg. 2021;161:448-54.
See Article page 448.

\section{Commentary: Enhanced recovery after surgery: Does ketorolac get in the WAE of anastomotic healing following esophagectomy?}

\author{
Shawn S. Groth, MD, MS, FACS
}

Following the success of Enhanced Recovery After Surgery (ERAS) protocols for lower gastrointestinal malignancies, ${ }^{1}$ similar pathways have emerged for patients undergoing esophagectomy. ${ }^{2,3}$ By standardizing perioperative patient care, ERAS pathways have the potential to improve the quality and efficiency of perioperative patient care, thereby reducing hospital length of stay, health care costs, perioperative morbidity, and potentially enhancing patient-centered outcomes. ${ }^{4}$ Central to ERAS pathways is multimodal perioperative analgesia, which often include selective or nonselective non-steroidal anti-inflammatory drugs (NSAIDs). ${ }^{5}$

During wound (anastomotic) healing, cyclooxygenase coverts arachidonic acid into prostaglandins, which play a central role in orchestrating a number of essential events, such as the activation of wound-associated epithelial (WAE) cells and fibroblasts. ${ }^{6}$ These actions are critical for promoting epithelialization of and providing tensile strength to the anastomosis. Therefore, cyclooxygenase inhibitors carry a theoretical risk of increasing the risk of

\footnotetext{
From the Division of Thoracic Surgery, Michael E. DeBakey Department of Surgery, Baylor College of Medicine, Houston, Tex.

Disclosures: Author has nothing to disclose with regard to commercial support.

Received for publication March 8, 2020; revisions received March 8, 2020; accepted for publication March 9, 2020; available ahead of print March 25, 2020.

Address for reprints: Shawn S. Groth, MD, MS, FACS, Division of Thoracic Surgery, Michael E. DeBakey Department of Surgery, One Baylor Plaza, BCM 390, Houston, TX 77030 (E-mail: Shawn.Groth@bcm.edu).

J Thorac Cardiovasc Surg 2021;161:456-7

0022-5223/\$36.00

Copyright (c) 2020 by The American Association for Thoracic Surgery

https://doi.org/10.1016/j.jtcvs.2020.03.049
}

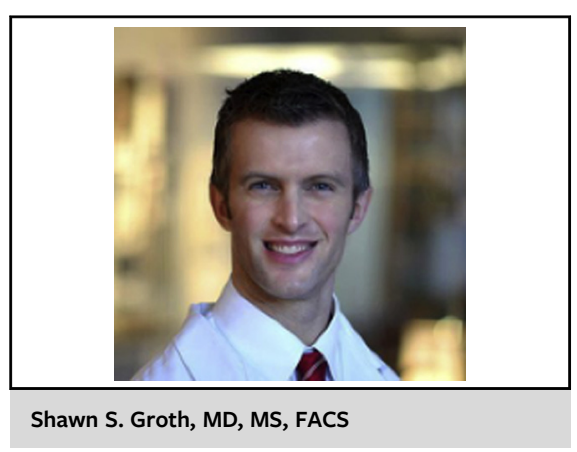

CENTRAL MESSAGE

As part of a multimodal, opioidlimiting, Enhanced Recovery After Surgery protocol, ketorolac does not increase the risk of anastomotic leak following esophagectomy.

anastomotic leaks. Indeed, there is (albeit not strong) evidence that NSAIDs may increase the risk of a leak following colectomy or proctectomy. ${ }^{7}$ Therefore, the possible benefits of NSAIDs in ERAS pathways must be balanced against their potential negative effects, including the risk of poor anastomotic healing.

In this issue of the Journal, Corsini and colleagues ${ }^{8}$ performed a retrospective review of 1016 patients who underwent esophagectomy for esophageal cancer at a single high-volume institution over a 12-year period (20062018) to assess the association between ketorolac use and clinically significant anastomotic leaks, defined as those leaks requiring endoscopic, surgical, or percutaneous intervention. Importantly, over the course of the study, the authors evolved to a practice of selective use of imaging when a leak was suspected, which limits the generalizability of their findings to clinically insignificant leaks detected on routine postoperative screening. 